Originally published as:

Andreas Stang, Angela Döring, Henry Völzke, Susanne Moebus, Karin Halina Greiser, Karl Werdan, Klaus Berger, Ute Ellert, Hanne Neuhauser.

Regional differences in body fat distributions among people with comparable body mass index: a comparison across six German population-based surveys.

(2011) European Journal of Preventive Cardiology, 18 (1), pp. 106-114.

DOI: 10.1097/HJR.0b013e32833b3305

This is an author manuscript.

The definitive version is available at: http://cpr.sagepub.com 


\title{
Regional differences in body fat distributions among people with comparable body mass index: a comparison across six German population-based surveys
}

\author{
Andreas Stang ${ }^{1}$, Angela Döring ${ }^{2}$, Henry Völzke ${ }^{3}$, Susanne Moebus ${ }^{4}$, Karin Halina Greiser ${ }^{5}$, Karl \\ Werdan $^{6}$, Klaus Berger ${ }^{7}$, Ute Ellert ${ }^{8}$, Hanne Neuhauser ${ }^{8}$ \\ ${ }^{1}$ Institut für Klinische Epidemiologie, Martin-Luther-Universität Halle-Wittenberg, Halle (Saale), \\ Germany. \\ ${ }^{2}$ Helmholtz-Zentrum München, Institut für Epidemiologie, Neuherberg, Germany. \\ ${ }^{3}$ Institut für Community Medicine, Ernst-Moritz-Arndt-Universitat, Greifswald, Germany. \\ ${ }^{4}$ Institut für Medizinische Informatik, Biometrie und Epidemiologie, Universitätsklinikum der Universität \\ Duisburg-Essen, Essen, Germany. \\ ${ }^{5}$ Institut für Medizinische Epidemiologie, Biometrie und Informatik, Martin-Luther-Universität Halle- \\ Wittenberg, Halle (Saale), Germany. \\ ${ }^{6}$ Universitätsklinik und Poliklinik Innere Medizin III, Martin-Luther Universität Halle-Wittenberg, Halle \\ (Saale), Germany. \\ 'Institut für Epidemiologie und Sozialmedizin, Universitätsklinikum, Münster, Germany. \\ ${ }^{8}$ Robert Koch-Institut, Berlin, Germany.
}

\begin{abstract}
Introduction: The mortality of circulatory diseases of the German population varies considerably across regions. The comparison of the regional distributions of cardiovascular risk factors can provide clues to the reasons for cardiovascular mortality differences. The aim of this study was to determine whether indirect measures of fat distribution within subgroups of comparable body mass indices (BMIs) differ by region in Germany.
\end{abstract}

Methods: We included six German population-based epidemiological studies conducted between 1997 and 2006 that included a detailed assessment of anthropometric measures including overall 15 215 people aged 45-74 years. We calculated mean values of BMI, waist circumference (WC), hip circumference $(H C)$, and waist-to-hip ratio (WHR). We estimated mean regional differences of WC, $H C$, and WHR within narrow ranges of BMI.

Results: BMI distributions across the study populations were very similar. However, body fat distributions as measured by WC within subgroups of similar BMIs differed considerably across regions. For example, among people with a BMI of 24.0-25.9, estimated WCs were on average 3.4 and $6.7 \mathrm{~cm}$ higher among men and women in Saxony-Anhalt than among men and women in Bavaria, respectively.

Conclusion: We provide evidence that the BMI distributions across six population-based surveys in Germany are very similar and that body fat distributions among people with comparable BMIs show relevant regional differences. Our observed WC differences might contribute to regional cardiovascular disease risk differences in Germany. Our findings may trigger further similar analyses across European populations to explain large area variations of cardiovascular disease burden. 


\section{Introduction}

The morality of circulatory diseases of the German population varies considerably across regions. For example, the age-standardized morality of circulatory diseases (International Classicification of Diseases: ${ }^{1} 100-199$; standard population: West Germany 1987) of the year 2003 varied between 302 per 100000 and 470 per 100,000 across federal states of Germany. East Germany has higher mortality rates of circulatory diseases than West Germany.

The comparison of the regional distributions of cardiovascular risk factors can provide clues to the reasons for these mortality differences. For example, the prevalence of smoking and hypertension is higher in East than West Germany, ${ }^{2,3}$ and the age-standardized prevalence of the metabolic syndrome varies between 16 and $24 \%$ across the federal states. ${ }^{4}$ The variation of body mass index (BMI) and body fat distribution may be further contributing factors to the observed mortality differences. ${ }^{5,6}$ According to a census ascertainment of a $1 \%$ household sample of the population in Germany aged 18 years or more in 1999 , the prevalences of obesity $\left(B M I \geq 30.0 \mathrm{~kg} / \mathrm{m}^{2}\right)$ based on self-reported height and weight varied among federal states from 8.8 to $15.4 \% .{ }^{7}$ Especially populations of East Germany show currently the highest prevalences of obesity. ${ }^{7}$

Conventionally, BMI has been used to define and classify overweight and obesity. However, BMI is only a crude measure of body fat distribution. ${ }^{8}$ It has been suggested that indirect measures of body fat distribution including waist (WC) and hip circumferences (HC) and waist-to-hip ratio (WHR) provide better insights into metabolic and cardiovascular risks and mortality associated with increased body fat than BMI alone..$^{9-12}$ Until now, regional comparisons of indirect measures of fat distribution within subgroups of comparable BMls have not been undertaken in Germany and many other countries. Therefore, the aim of this study was to determine whether indirect measures of fat distribution within subgroups of comparable BMls differ by region in Germany. For this purpose, we analyzed data of six recent large population-based surveys in Germany including 15,215 people.

\section{Materials and methods}

We included German population-based epidemiological studies that were conducted between 1997 and 2006 and performed a detailed assessment of anthropometric measures: the German National Health Interview and Examination Survey (Bundesgesundheitssurvey, BGS) from 1998 comprising 120 sampling points all over Germany, ${ }^{13}$ the KORA S4 study in Augsburg, Bavaria, ${ }^{14}$ the Study of Health in Pomerania (SHIP-0) in West Pomerania, Northeast Germany, ${ }^{15}$ the Heinz Nixdorf Recall Study (HNR) in the cities of Essen, Bochum, and Mulheim of the Ruhrarea of North RhineWestphalia, ${ }^{6}$ the Dortmund Health Study (DHS) in the city Dortmund, North Rhine-Westphalia, ${ }^{17}$ and the Cardiovascular Disease, Living and Ageing in Halle Study (CARLA) in the city of Halle, SaxonyAnhalt. ${ }^{18}$ As the BGS with overall 120 sampling points all over Germany does not provide regional estimates of WC and $\mathrm{HC}$, we did not include these data for the regional comparisons.

Each study was reviewed by local ethics committees and all participants gave written informed consent. In all studies, weight, height, WC and HC were measured by a comparable study protocol (supplementary material, Table A1). Body weight and height were measured to the nearest $0.1 \mathrm{~kg}$ and $0.1 \mathrm{~cm}$ (exception: DHS study to the nearest $0.5 \mathrm{~cm}$ ), respectively, using standardized equipment and procedures. Waist and hip circumferences were measured in underwear. The WC measurement was made at minimal inspiration to the nearest $0.5 \mathrm{~cm}$ (BGS) or $0.1 \mathrm{~cm}$ (all other studies), midway between the last rib and the iliac crest. $\mathrm{HC}$ was measured at the widest circumference over the buttocks to the nearest $0.5 \mathrm{~cm}$ (BGS) or $0.1 \mathrm{~cm}$ (all other studies) with the exception of the HNR study that measured $\mathrm{HC}$ midway between the iliac crest and the crotch. The DHS study measured only height and weight and therefore was excluded for the regional comparison of WC, HC and WHR. More details of the study protocols are available on request. In all studies, the study personnel was trained and certified in anthro-pometric measurement. The study personnel was regularly monitored throughout the recruitment. The study regions of the surveys are presented in supplementary material Figure $A 1$, and core study characteristics are summarized in Supplementary material, Table A2.

We categorized participants according to cut-offs published earlier for $\mathrm{BMI}$ according to the $\mathrm{WHO}^{19}$ (overweight: $25.0-29.9 \mathrm{~kg} / \mathrm{m}^{2}$, obesity: $\geq 30 \mathrm{~kg} / \mathrm{m}^{2}$ ) and for WC and WHR according to NCEP ATP III ${ }^{20}$ (increased waist: men $>102 \mathrm{~cm}$, women $>88 \mathrm{~cm}$; increased WHR: men $>1.00$, women $>0.85$ ). 


\section{Statistical methods}

Sample data of the BGS were weighted to account for the sampling design and to produce estimates representative for East and West Germany, respectively. To maximize the number of surveys that can be used for regional comparisons, analyses were restricted to participants aged between 45 and 74 years enabling the BMI comparison of five regional surveys and the German-wide BGS. Participants with missing data on BMI, waist or $\mathrm{HC}$ were excluded. With the exception of one survey (BGS, West Germany: $1.2 \%$ missing data), the proportion of participants with missing data was less than $1 \%$ in each study.

We calculated sex-stratified and age-stratified mean and median values of BMI, WC, HC, and WHR. In addition, we calculated sex-stratified and age-stratified prevalences of overweight, obesity, increased WC, and increased WHR.

Furthermore, we calculated age-truncated (45-74 years) mean values and age-standardized prevalences using the population figures of Germany as of 31 December 2003 as the standard population. To visualize the BMI distributions, we used schematic box-and-whisker plots according to Tukey. ${ }^{21}$ To estimate mean regional differences of WC, HC, or WHR within narrow ranges of BMI, we computed linear regression models with $\mathrm{WC}, \mathrm{HC}$, or WHR as the continuous outcome variable within narrow BMI subgroups $20.0-21.9,22.0-23.9, \ldots, 34.0-35.9 \mathrm{~kg} / \mathrm{m}^{2}$, separately for men and women. We used disjoint indicator variables for the regional surveys (HNR, SHIP-0, CARLA) with KORA-S4, Augsburg as reference region. For example, to estimate regional differences of WC within BMI subgroups, we set up linear regression models within each BMI subgroup and sex: $W C=$ intercept $+b 1(H N R)+b 2(S H I P-0)+b 3(C A R L A)$. The intercepts of these models can be interpreted as the estimated mean WCs, HCs, or WHRs in Augsburg within BMI subgroups. The regression coefficients can be interpreted as estimated difference of WC, HC, and WHR, respectively between the reference and comparison regions. For example, among men with a BMI of 24.0-25.9, the intercept of the linear regression was 93.0 and can be interpreted as the estimated mean value of WC in KORA-S4, Augsburg. The regression coefficient of the indicator variables provide estimated mean difference of WC compared with the reference group, that is, KORA-S4, Augsburg: the regression coefficient for the CARLA study was 3.4 , indicating a mean difference of $+3.4 \mathrm{~cm}$ between KORA-S4, Augsburg and CARLA with men having on average $3.4 \mathrm{~cm}$ higher WCs within the BMI group of 24.0-25.9 than men in KORA-S4, Augsburg.

To study the stability of these linear regression results, we performed several sensitivity analyses: we computed regression models within narrower BMI ranges $(20.0-20.9,21.0-21.9, \ldots, 30.0-30.9)$ to further decrease residual variability of BMI within subgroups. We adjusted the regression models for height. We used the KORA-S4 and SHIP-0 studies to run these regression models among participants at an extended age range of 25-74 years as these studies covered this broader age range.

\section{Results}

Mean and median BMls across the study populations of men and women were very similar. Varying degrees of slight right skewness of the BMI distributions explain the somewhat varying prevalences of obesity across studies. In a sensitivity analysis, we studied the BMI distribution within a broader age range of 25-74 years of those studies that included this age range (KORA-S4, SHIP-0, DHS, and BGS). Only 43 out of 15213 participants $(0.3 \%)$ had BMls below 18.5 (Table 1, Figure 1).

The CARLA Study (Saxony-Anhalt) had the highest mean WC among both men and women whereas the mean $\mathrm{HC}$ was quite low among men and high among women in this study. The age-standardized prevalence of increased WC was highest in the CARLA and the BGS-East studies (East Germany) among both men and women. Mean WHR values were highest in the HNR (North Rhine-Westphalia) and CARLA studies (Saxony-Anhalt) among both men and women (Table 2).

WCs within subgroups of comparable BMI differed by region. Compared with the KORA-S4 Study (Bavaria), WCs were lower among participants of the SHIP-0 Study (Mecklenburg-West Pomerania), very similar among participants of the HNR Study (North Rhine-Westphalia) and considerably higher 
among participants of the CARLA Study (Saxony-Anhalt). For example, within the subgroup of men with a BMI of 24.0-25.9, the mean WC was $93.0 \mathrm{~cm}$ in the KORA-S4 Study (Bavaria). Compared with Bavaria, the estimated WC was on average 0.3 and $1.9 \mathrm{~cm}$ lower among men of the HNR (North Rhine-Westphalia) and the SHIP-0 studies (Mecklenburg-West Pomerania), respectively. However, estimated WCs were on average $3.4 \mathrm{~cm}$ higher among men of the CARLA Study (Saxony-Anhalt). Among women, estimated mean differences of WC were even larger between the KORA-S4 (Bavaria) and the CARLA studies (Saxony-Anhalt) with estimated mean differences between 4.2 and $8.1 \mathrm{~cm}$ depending on the BMI subgroup. WC differences between the surveys were most prominent within BMI ranges of $22-31 \mathrm{~kg} / \mathrm{m}^{2}$. WC and $\mathrm{HC}$ estimates for the BMI subgroups below 22 or above 31 were too unreliable for a meaningful interpretation. Participants of the HNR (North Rhine-Westphalia) and SHIP-0 studies (Mecklenburg-West Pomerania) had lower HCs within BMI subgroups than participants of the KORA-S4 Study (Bavaria). Men of the CARLA Study (Saxony-Anhalt) had lower HCs than men of the KORA-S4 Study whereas women of the CARLA Study had HC which were very comparable with women of the KORA-S4 Study (Figures 2 and 3; and online supplementary material, Table A3A5, Figure A2).

The regional WC differences among participants with comparable BMls aged 25-74 years (KORA-S4 and SHIP-0 studies) were very similar to those among participants aged $45-74$ years. Additional adjustments for body height, age, or BMI did not markedly change our results. Similarly, the regional comparison of WC within even narrower subgroups of BMI (that is, 20.0-20.9, 21.0-21.9, etc.) did not markedly change our results.

\section{Discussion}

In this study, we provide evidence that the BMI distributions across six population-based surveys in Germany are very similar and that body fat distributions among people with comparable BMls show relevant regional differences. We observed mean differences of WC of up to $8.1 \mathrm{~cm}$ within narrow subgroups of BMI between surveys. Different body fat distributions predict different risks of cardiovascular diseases. ${ }^{10,22-24}$ For example, the Nurses Health Study ${ }^{22}$ and the INTERHEART Study

${ }^{23}$ showed that a BMI-adjusted increase of WC or WHR increases the risk of myocardial infarction among both men and women. Recent results of the European Prospective Investigation into Cancer and Nutrition Study showed that for a given BMI in men and women, a $5 \mathrm{~cm}$ higher WC was associated with a risk increase of death of $17 \%$ among men and $13 \%$ among women. ${ }^{11}$

Obviously, the sole comparison of $\mathrm{BMI}$ across regional surveys may mask important differences in health risks because body fat distributions may differ among populations with comparable BMls. Earlier studies that analyzed regional distributions of BMI in Germany used mainly prevalence measures of overweight and obesity for comparison, and unanimously concluded that the prevalence of overweight and obesity is higher in East than West Germany. ${ }^{5,7}$ Our study of the complete BMI distributions (i.e. BMI as a continuous variable) showed that there were only small regional differences of the BMI distributions among the surveyed people aged 45-74 years. Dichotomization or categorization of the BMI distribution at predefined cut-offs (overweight: BMI $25.0-29.9 \mathrm{~kg} / \mathrm{m}^{2}$, obesity: $\mathrm{BMI} \geq 30.0 \mathrm{~kg} / \mathrm{m}^{2}$ ) resulted in some regional prevalence differences for overweight and obesity because the BMI distributions showed varying degrees of slight right-skewness.

Earlier comparisons of the regional distribution of WC and HC showed that East German women have higher WCs (on average $+1.7 \mathrm{~cm}$ ) than West German women while men had very similar WC and HC. ${ }^{5}$ However, comparisons of WC and $\mathrm{HC}$ became complicated if BMls differ because BMI is strongly associated with WC and HC. ${ }^{24,25}$ As early as 1994 Stevens et al. ${ }^{26}$ studied WC among Black and White women within broad subgroups of BMI and showed that Black women had a smaller WC than White women within subgroups of BMI. We observed that even within a single ethnic group, body fat distributions among participants with comparable BMls considerably differ by regions. We hypothesize that regional differences regarding dietary and smoking habits, and physical activity (leisure time and at the workplace), which all influence the body fat distribution, may at least partially explain the regional differences of body fat distributions in Germany. A detailed comparison of these lifestyle factors among people with comparable BMI of the surveys may give further insights into the reasons for the differences. 
The considerably higher mean WCs among people from Saxony-Anhalt (CARLA Study) compared with people from Mecklenburg-West Pomerania (SHIP-0 Study), both East German regions, are in line with results of a recent national cross-sectional study (GEMCAS). This study revealed that agestandardized and sex-standardized prevalences of increased WCs according to NCEP-ATP III ${ }^{20}$ were highest in Saxony-Anhalt (42.1\%), where the CARLA Study population is located. Corresponding prevalences in Mecklenburg-West Pomerania (study region of the SHIP-0 Study), North RhineWestphalia (study region of the HNR and DHS studies), and Bavaria (study region of the KORA-S4 Study) were $36.7,37.5$, and $35.7 \%$, respectively. ${ }^{27}$

There are several factors that limit our results. First, all surveys suffered from non-response. Analyses of non-participants who filled in short questionnaires of some surveys gave some ideas about potential selection effects. In the KORA-S4 Study, a higher prevalence of coronary artery disease, diabetes mellitus, and smoking was observed among non-participants than participants. ${ }^{28}$ Similarly, in the HNR Study a higher prevalence of smoking was found among non-participants than participants. ${ }^{29}$ It is difficult to speculate in which way these selection effects may have influenced the regional comparisons. Second, our interpretations hinge on the assumption that the methods of anthropometric measurements were comparable across the six surveys. With the exception of the $\mathrm{HC}$ measurement in the HNR Study, standard operating procedures for anthropometric measurements were identical. Experienced researchers (A.D. and others) of the KORA-S4 Study trained and certified the study personnel of the HNR Study, the SHIP-0 Study, and the CARLA Study. As comparative measurement accuracy studies across the presented surveys were not conducted, it is difficult to speculate if and how much measurement biases contributed to our results. Third, our findings are based on participants aged 45-74 years and may not necessarily be generalizable to younger or older people. Fourth, we could not account for different calendar study periods of recruitment and therefore our comparison of the obesity prevalence across studies is not corrected for secular trends.

\section{Conclusion}

We provide evidence that although BMI distributions across six population-based surveys in Germany are very similar, body fat distributions among people with comparable BMls show considerable regional differences. Our observed WC differences might explain regional cardiovascular disease risk differences of $10-15 \%$ and total mortality differences of $13-17 \%$ depending on sex and BMI.

Therefore, indices of body fat distribution should not be prematurely dismissed as contributing factors to regional differences in cardiovascular morbidity and mortality in Germany. Our findings may trigger further similar analyses across European populations, which may contribute to the explanation of large area variations of the cardiovascular disease burden and mortality.

\section{Acknowledgements}

The authors would like to thank the participants, the personnel, and the cooperating research partners of all the six studies. They also thank Mareike Kunze for the preparation of the figures.

\section{Funding}

The KORA research platform (KORA, Cooperative Research in the Region of Augsburg) was initiated and financed by the GSF-National Research Centre for Environment and Health, which is funded by the German Federal Ministry of Education and Research and by the State of Bavaria. The authors thank the Heinz Nixdorf Foundation (Chairman: Dr Jur G. Schmidt) for their generous financial support of the Heinz Nixdorf Recall Study. This study was also supported by the German Ministry of Education and Science. The authors thank K. Lauterbach (Department of Health Economy and Epidemiology, University of Cologne) for his valuable contribution to the study. The population-based Study of Health in Pomerania (SHIP) is part of the Community Medicine Research Net of the University of Greifswald, Germany, which is funded by grants from the German Federal Ministry of Education and Research (BMBF, grant no 01ZZ96030), the Ministry for Education, Research and Cultural Affairs, and the 
Ministry for Social Affairs of the Federal State of Mecklenburg-West Pomerania. The CMR encompasses several research projects which share data from the population-based SHIP ( http://ship.community-medicine.de ). The German National Health Interview and Examination Survey was funded by the German Ministry of Health. The CARLA Study was funded by a grant from the Deutsche Forschungsgemeinschaft (DFG, German Research Foundation) as part of the Collaborative Research Center 598 'Heart failure in the elderly - cellular mechanisms and therapy' at the Medical Faculty of the Martin-Luther-University Halle-Wittenberg (DFG grant No. SFB 598-02) by an individual grant from the DFG (DFG grant No Ha 2419/2-1), by a grant of the Wilhelm-Roux Programme of the Martin-Luther-University Halle-Wittenberg, and by the Federal Employment Office. The Dortmund Health Study was supported by the German Migraine and Headache Society (DMKG) and by unrestricted grants of equal share from Astra Zeneca, Berlin Chemie, Boots Healthcare, GlaxoSmithKline, McNeil Pharma, MSD Sharp and Dohme, Pfizer to the University of Muenster. 


\section{References}

1. World Health Organization. The international statistical classification of diseases and related health problems, $10^{\text {th }}$ ed. Geneva: World Health Organization, 1992.

2. Völzke H, Neuhauser H, Moebus S, Baumert J, Berger K, Stang A, et al. Rauchen: Regional disparities in smoking among adults in Germany. Deutsches A" rzteblatt 2006; 103:

2784-2790.

3. Thamm M. Blood pressure in Germany - current status and trends. Gesundheitswesen 1999; 61 (Suppl): 90-93.

4. Moebus S, Hanisch J, Bramlage P, Lo" sch C, Hauner H, Wasem J, et al. Regional differences in the prevalence of the metabolic syndrome in primary care practices in Germany. Dtsch Arztebl Int 2008; 105: 207-213.

5. Bergmann KE and Mensink GBM. Anthropometric measures, overweight and obesity. Gesundheitswesen 1999; 61: S115-S120.

6. Sehested TS, Hansen TW, Olsen MH, Abildstrom SZ, Rasmussen S, Ibsen H, et al. Measures of overweight and obesity and risk of cardiovascular disease: a population-based study. Eur $\mathrm{J}$ Cardiovasc Prev Rehabil 2010. [Epub ahead of print].

7. Benecke A, Vogel H. Overweight and adipositas Vol 16. Berlin: Robert Koch-Institut.

Gesundheitsberichtsersttung des Bundes. Robert Koch-Institut; 2003. pp. 1-27.

8. Rothman KJ. BMI-related errors in the measurement of obesity. Int J Obes (Lond) 2008; 32(Suppl 3): S56-S59.

9. Snijder MB, van Dam RM, Visser M and Seidell JC. What aspects of body fat are particularly hazardous and how do we measure them? Int J Epidemiol 2006; 35: 83-92.

10. De Koning L, Merchant AT, Pogue $J$ and Anand SS. Waist circumference and waist-to-hip ratio as predictors of cardiovascular events: meta-regression analysis of prospective studies. Eur Heart $\mathrm{J}$ 2007; 28: 850-856.

11. Pischon T, Boeing H, Hoffmann K, Bergmann M, Schulze MB, Overvad K, et al. General and abdominal adiposity and risk of death in Europe. N Engl J Med 2008; 359: 2105-2120.

12. National Heart, Lung, and Blood Institute. Clinical guidelines on the identification, evaluation, and treatment of overweight and obesity in adults. Bethesda, MD: National Institutes of Health. National Heart, Lung, and Blood Institute, 1998.

13. Bellach BM. The 1998 Federal Health Survey. Experiences, results, perspectives.

Gesundheitswesen 1999; 61(Suppl): 55-56. (Spec No: S55-S56.

14. Meisinger C, Heier M, Vo" Izke H, Lo" wel H, Mitusch R, Hense HW, et al. Regional disparities of hypertension prevalence and management within Germany. J Hypertens 2006; 24: 293-299.

15. Volzke H, Schwahn C, Wolff B, Mentel R, Robinson DM, Kleine V, et al. Hepatitis B and C virus infection and the risk of atherosclerosis in a general population. Atherosclerosis 2004; 174: 99-103. 16. Schmermund A, Möhlenkamp S, Stang A, Grönemeyer D, Seibel R, Hirche H, et al. Assessment of clinically silent atherosclerotic disease and established and novel risk factors for predicting myocardial infarction and cardiac death in healthy middle-aged subjects: rationale and design of the Heinz Nixdorf RECALL Study. Risk Factors, Evaluation of Coronary Calcium and Lifestyle. Am Heart J 2002; 144: 212-218.

17. Vennemann MM, Hummel $\mathrm{T}$ and Berger $\mathrm{K}$. The association between smoking and smell and taste impairment in the general population. J Neurol 2008; 255: 1121-1126.

18. Greiser KH, Kluttig A, Schumann B, Kors JA, Swenne CA, Kuss O, et al. Cardiovascular disease, risk factors and heart rate variability in the elderly general population: design and objectives of the CARdiovascular disease, Living and Ageing in Halle (CARLA) Study. BMC Cardiovasc Disord 2005; 5: 33.

19. World Health Organization. World Health Organization consultation on obesity: Preventing and managing the global epidemic. Geneva: Division of Noncommunicable Diseases, Programme of Nutrition, Family and Reproductive Health, World Health Organization, 1998.

20. Expert Panel on Detection, Evaluation, and Treatment of High Blood Cholesterol in Adults.

Executive Summary of The Third Report of the National Cholesterol Education Program (NCEP).

Executive Summary of the Third Report of the National Cholesterol Education Program

(NCEP) Expert Panel on Detection, Evaluation, and Treatment of High Blood Cholesterol In Adults

(Adult Treatment Panel III). JAMA 2001; 285: 2486-2497.

21. Tukey JW. Easy summaries - numerical and graphical. In: Tukey JW (ed.) Exploratory data analysis. Reading: Addison-Wesley Publishing Company, 1977, pp.27-56. 
22. Rexrode KM, Carey VJ, Hennekens CH, Walters EE, Colditz GA, Stampfer MJ, et al. Abdominal adiposity and coronary heart disease in women. JAMA 1998; 280: 1843-1848.

23. Yusuf S, Hawken S, Ounpuu S, Bautista L, Franzosi MG, Commerford P, et al. Obesity and the risk of myocardial infarction in 27000 participants from 52 countries: a case-control study. Lancet 2005; 366: 1640-1649.

24. Van Dis I, Kromhout D, Geleijnse JM, Boer JMA and Verschuren WMM. Body mass index and waist circumference predict both 10-year nonfatal and fatal cardiovascular disease risk: study conducted in 20000 Dutch men and women aged 20-65 years. Eur J Cardiovasc Prev

Rehabil 2009; 16: 729-734.

25. Stevens J, McClain JE and Truesdale KP. Selection of measures in epidemiologic studies of the consequences of obesity. Int J Obes (Lond) 2008; 32(Suppl 3): S60-S66.

26. Stevens J, Plankey MW, Keil JE, Rust PF, Tyroler HA and Davis CE. Black women have smaller abdominal girths than white women of the same relative weight. J Clin Epidemiol 1994; 47: 495-499. 27. Hauner $\mathrm{H}$, Bramlage $\mathrm{P}$, Lösch $\mathrm{C}$, Schunkert $\mathrm{H}$, Wasem J, Jöckel KH, et al. Overweight, obesity and high waist circumference - regional differences in prevalence in primary medical care. Deutsches Ärzteblatt 2008; 105: 827-833.

28. Hoffmann W, Terschu" ren C, Holle R, Kamtsiuris P, Bergmann M, Kroke A, et al. The problem of response in epidemiologic studies in Germany (Part II). Gesundheitswesen 2004; 66: 482-491. 29. Stang A, Moebus S, Dragano N, Beck EM, Möhlenkamp S, Schmermund A, et al. Baseline recruitment and analyses of nonresponse of the Heinz Nixdorf Recall Study: identifiability of phone numbers as the major determinant of response. Eur J Epidemiol 2005; 20: 489-496. 


\section{Tables and Figures}

Table 1. Distribution of body mass index (BMI) across population-based surveys in Germany among participants aged $45-74$ years

\begin{tabular}{|c|c|c|c|c|c|c|c|c|c|}
\hline & \multirow[b]{2}{*}{$N$} & \multirow[b]{2}{*}{ Mean } & \multirow[b]{2}{*}{ SD } & \multirow[b]{2}{*}{ Median } & \multirow[b]{2}{*}{$\mathrm{P} 25$} & \multirow[b]{2}{*}{ P75 } & \multicolumn{3}{|c|}{$\begin{array}{l}\text { Age-standardized prevalences in percent } \\
\text { (standard errors) of BMI categories }\end{array}$} \\
\hline & & & & & & & Normal weight & Overweight & Obesity \\
\hline \multicolumn{10}{|l|}{ Men } \\
\hline KORA-S4 & 1253 & 28.3 & 4.0 & 27.8 & 25.7 & 30.4 & $17(1.1)$ & $55(1.4)$ & $28(1.3)$ \\
\hline HNR & 2373 & 28.2 & 3.9 & 27.7 & 25.6 & 30.2 & $19(0.8)$ & $54(1.0)$ & $27(0.9)$ \\
\hline DHS & 436 & 28.8 & 4.3 & 28.6 & 26.0 & 31.0 & $18(1.9)$ & $48(2.5)$ & $33(2.3)$ \\
\hline SHIP-0 & 1138 & 28.4 & 4.0 & 28.1 & 25.7 & 30.7 & $19(1.2)$ & $50(1.5)$ & $30(1.4)$ \\
\hline CARLA & 753 & 28.3 & 4.3 & 27.8 & 25.4 & 30.9 & $23(1.6)$ & 48 (1.9) & $29(1.7)$ \\
\hline BGS-West Germany & 1080 & 27.9 & 4.0 & 27.6 & 25.4 & 29.8 & $21(1.2)$ & $56(1.4)$ & $24(1.2)$ \\
\hline BGS-East Germany & 550 & 28.3 & 2.8 & 28.3 & 25.7 & 30.5 & $19(2.3)$ & $52(2.9)$ & $28(2.6)$ \\
\hline \multicolumn{10}{|l|}{ Women } \\
\hline KORA-S4 & 1257 & 28.4 & 5.1 & 27.7 & 24.7 & 31.2 & $28(1.2)$ & $40(1.4)$ & $32(1.3)$ \\
\hline HNR & 2393 & 27.6 & 5.2 & 27.0 & 23.9 & 30.5 & $34(1.0)$ & $37(1.0)$ & $28(0.9)$ \\
\hline DHS & 447 & 27.9 & 5.2 & 27.4 & 24.0 & 31.2 & $34(2.2)$ & $36(2.3)$ & $30(2.1)$ \\
\hline SHIP-0 & 1133 & 28.6 & 5.2 & 27.9 & 24.7 & 31.6 & $26(1.3)$ & $39(1.5)$ & $34(1.4)$ \\
\hline CARLA & 664 & 28.6 & 5.6 & 28.0 & 24.6 & 31.6 & $30(1.8)$ & $36(1.9)$ & 34 (1.9) \\
\hline BGS-West Germany & 1099 & 27.8 & 5.9 & 27.0 & 24.1 & 30.7 & $32(1.3)$ & $39(1.3)$ & $28(1.2)$ \\
\hline BGS-East Germany & 637 & 28.6 & 3.7 & 28.1 & 25.1 & 31.8 & $24(2.3)$ & $40(2.6)$ & $36(2.6)$ \\
\hline
\end{tabular}

Mean and median BMI values are crude values, age-adjustment of mean BMI values resulted in virtually no changes, normal weight: BMI I8.5-24.9, overweight: BMI 25.0-29.9, obesity: BMI 30+ kg/ $\mathrm{m}^{2}$. BGS, Bundes-Gesundheits survey; BMI, body mass index; CARLA, Cardiovascular Disease, Living and Ageing in Halle Study; DHS, Dortmund Health Study; HNR, Heinz Nixdorf Recall Study; SD, standard deviation; SHIP, Study of Health in Pomerania.

Table 2. Distribution of waist and hip circumference and waist-to-hip ratio across population-based surveys in Germany among participants aged $45-74$ years

\begin{tabular}{|c|c|c|c|c|c|c|c|c|c|c|c|}
\hline & \multirow[b]{3}{*}{$N$} & \multicolumn{4}{|c|}{ Waist circumference $(\mathrm{cm})$} & & & \multicolumn{4}{|c|}{ Waist-to-hip ratio } \\
\hline & & \multirow[b]{2}{*}{ Mean } & \multirow[b]{2}{*}{ SD } & \multicolumn{2}{|c|}{$\begin{array}{l}\text { Increased waist } \\
\text { circumference }^{a}\end{array}$} & \multicolumn{2}{|c|}{$\begin{array}{l}\text { Hip } \\
\text { circumference }(\mathrm{cm})\end{array}$} & \multirow[b]{2}{*}{ Mean } & \multirow[b]{2}{*}{ SD } & \multicolumn{2}{|c|}{$\begin{array}{l}\text { Increased } \\
\mathrm{WHR}^{\mathrm{a}}\end{array}$} \\
\hline & & & & $\%$ & SE & Mean & SD & & & $\%$ & SE \\
\hline \multicolumn{12}{|l|}{ Men } \\
\hline KORA-S4 & 1253 & 100.3 & 10.3 & 37 & 1.4 & 105.0 & 7.5 & 0.95 & 0.054 & 15 & 1.0 \\
\hline HNR & 2373 & 100.3 & 10.7 & 40 & 1.0 & 102.3 & 8.2 & 0.98 & 0.061 & 34 & 1.0 \\
\hline SHIP-0 & 1138 & 98.9 & 10.8 & 34 & 1.4 & 103.9 & 7.8 & 0.95 & 0.056 & 15 & 1.1 \\
\hline CARLA & 753 & 103.6 & 11.3 & 10 & 1.9 & 103.3 & 8.2 & 1.00 & 0.055 & 51 & 1.9 \\
\hline BGS-West Germany & 1080 & 100.8 & 10.9 & 40 & 1.4 & 106.5 & 7.7 & 0.95 & 0.059 & 14 & 1.0 \\
\hline BGS-East Germany & 550 & 101.7 & 7.7 & 47 & 2.9 & 106.8 & 5.2 & 0.95 & 0.042 & 17 & 2.2 \\
\hline \multicolumn{12}{|l|}{ Women } \\
\hline KORA-S4 & 1257 & 89.2 & 12.3 & 50 & 1.4 & 107.3 & 10.8 & 0.83 & 0.063 & 35 & 1.3 \\
\hline HNR & 2393 & 88.4 & 12.8 & 46 & 1.0 & 104.1 & 11.5 & 0.85 & 0.069 & 45 & 1.0 \\
\hline SHIP-0 & 1133 & 87.7 & 12.1 & 45 & 1.5 & 106.4 & 11.0 & 0.82 & 0.060 & 27 & 1.3 \\
\hline CARLA & 664 & 95.6 & 13.8 & 66 & 1.9 & 108.2 & 11.6 & 0.88 & 0.063 & 71 & 1.8 \\
\hline BGS-West Germany & 1099 & 89.5 & 13.9 & 49 & 1.4 & 107.8 & 12.0 & 0.83 & 0.068 & 31 & 1.3 \\
\hline BGS-East Germany & 637 & 92.3 & 9.2 & 61 & 2.6 & 109.5 & 7.7 & 0.84 & 0.051 & 40 & 2.6 \\
\hline
\end{tabular}

The means and medians of the waist and hip circumference, and waist-to-hip ratio (WHR) were virtually the same, respectively. BGS, BundesGesundheits survey; CARLA, Cardiovascular Disease, Living and Ageing in Halle Study; DHS, Dortmund Health Study; HNR, Heinz Nixdorf Recall

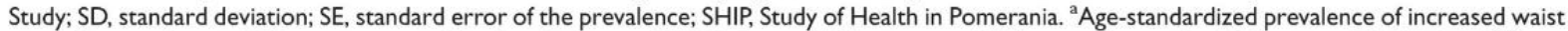
circumference (men $>102 \mathrm{~cm}$, women $>88 \mathrm{~cm}$ ) and increased WHR (men $>1.00$, women $>0.85$ ) according to the definitions of NCEP ATP III ${ }^{20}$; age standard: Germany 2003 population 
Figure 1. Distribution of body mass index among men and women aged 45-74 years of five population-based regional surveys and of the German National Health Examination Survey. Box width varies with study size. Whiskers indicate observations within the lower and upper fence [i.e.

$1.5^{*}$ interquartile range (IQR) below 25th percentile and $1.5^{*} \mathrm{IQR}$ above 75 th percentile]. Plus symbols indicate observations outside the fences. Filled squares indicate mean body mass index (BMI) values. Horizontal lines within the boxes indicate the median BMI values. Dotted lines indicate the overall (across all studies) 25th percentile, median, and 75th percentile of the BMI distribution. All analyses are crude analyses. BGS, Bundes-Gesundheits survey; CARLA, Cardiovascular Disease, Living and Ageing in Halle Study; DHS, Dortmund Health Study; HNR, Heinz Nixdorf Recall Study; SHIP, Study of Health in Pomerania.




Figure 2. Estimated mean difference of waist circumference $(\mathrm{cm})$ within narrow body mass index (BMI) ranges across population-based surveys of participants aged 45-74 years in Germany (reference group: KORA-S4 survey, Augsburg, Bavaria). Regression models were restricted to BMI values of 20-35 to avoid sparse data bias; $\Delta$, estimated mean difference in comparison to the KORAS4 Study (Bavaria); BMI adjusted, estimated mean difference of waist-to-hip ratios adjusted for BMI (including all participants). CARLA, Cardiovascular Disease, Living and Ageing in Halle Study; Cl, confidence interval; HNR, Heinz Nixdorf Recall Study; SHIP, Study of Health in Pomerania.
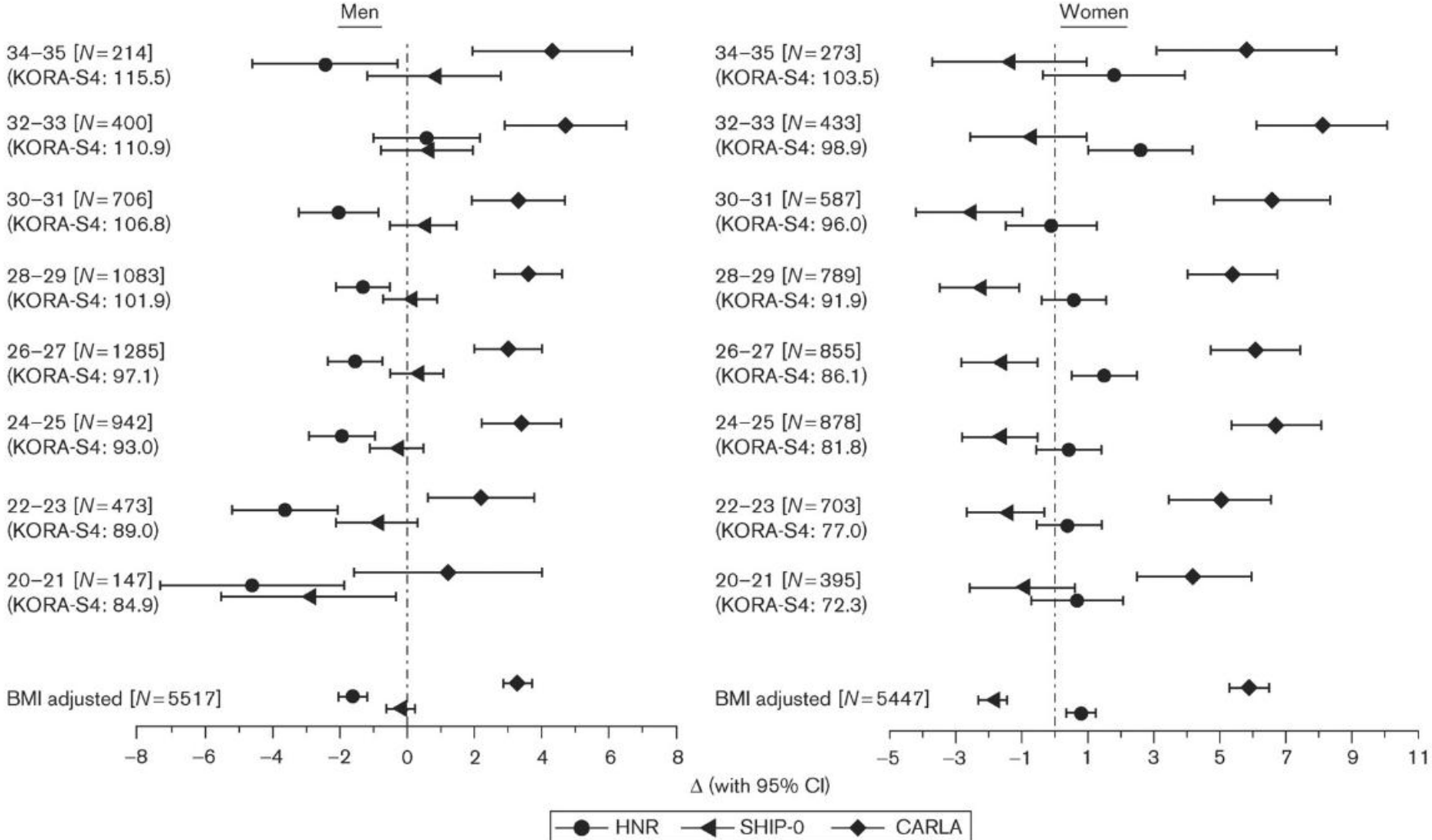

- HNR $\longleftarrow$ SHIP-O $\multimap$ CARLA 
Figure 3. Estimated mean difference of hip circumference $(\mathrm{cm})$ within narrow body mass index (BMI) ranges across population-based surveys of participants aged 45-74 years in Germany (reference Group: KORA-S4 survey, Augsburg, Bavaria). Regression models were restricted to BMI values of 20-35 to avoid sparse data bias; $\Delta$, estimated mean difference in comparison to the KORA-S4 Study (Bavaria); BMI adjusted, estimated mean difference of waist-to-hip ratios adjusted for BMI (including all participants). CARLA, Cardiovascular Disease, Living and Ageing in Halle Study; $\mathrm{Cl}$, confidence interval; HNR, Heinz Nixdorf Recall Study; SHIP, Study of Health in Pomerania.

Men

34P-35 $[N=214]$
(KORA-S4: 115.2)

$32-33[N=400]$

(KORA-S4: 111.7)

$32-31[N=706]$

(KORA-S4: 108.7)

28-29 [ $N=1083$ ]

(KORA-S4: 105.4)

26-27 [ $N=1285]$

(KORA-S4: 103.1)

24-25 [ $N=942]$

(KORA-S4: 100.4)

22-23 [ $N=473]$

(KORA-S4: 97.9)

$20-21[N=147]$

(KORA-S4: 95.1)
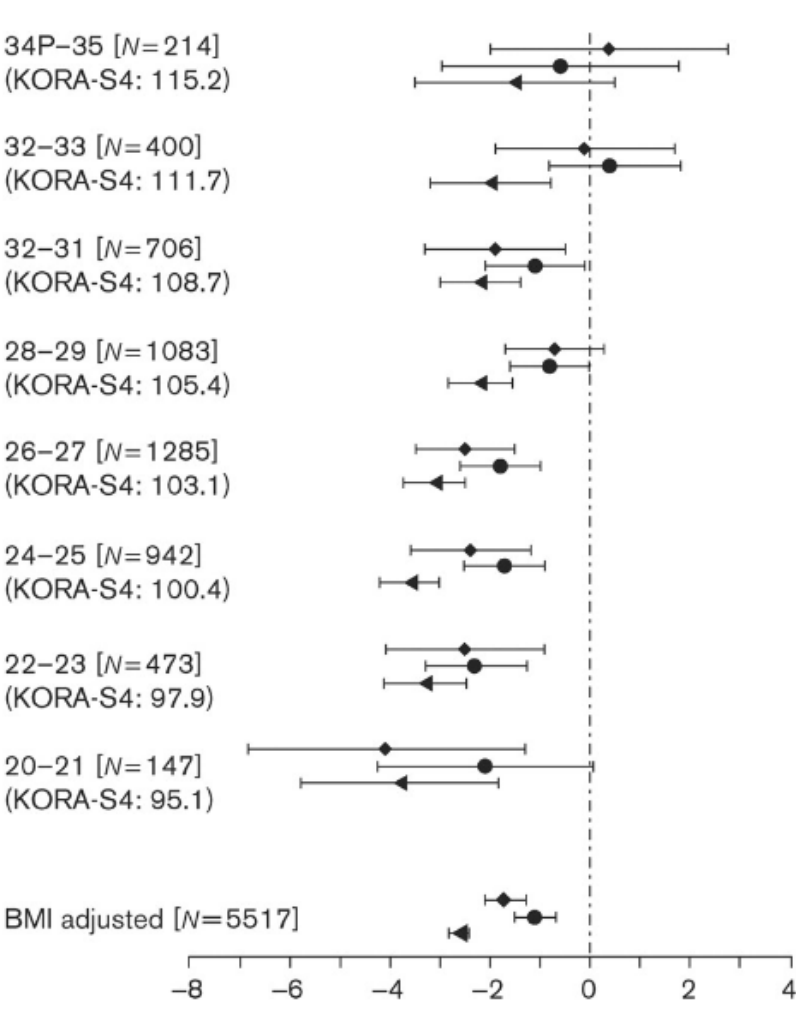

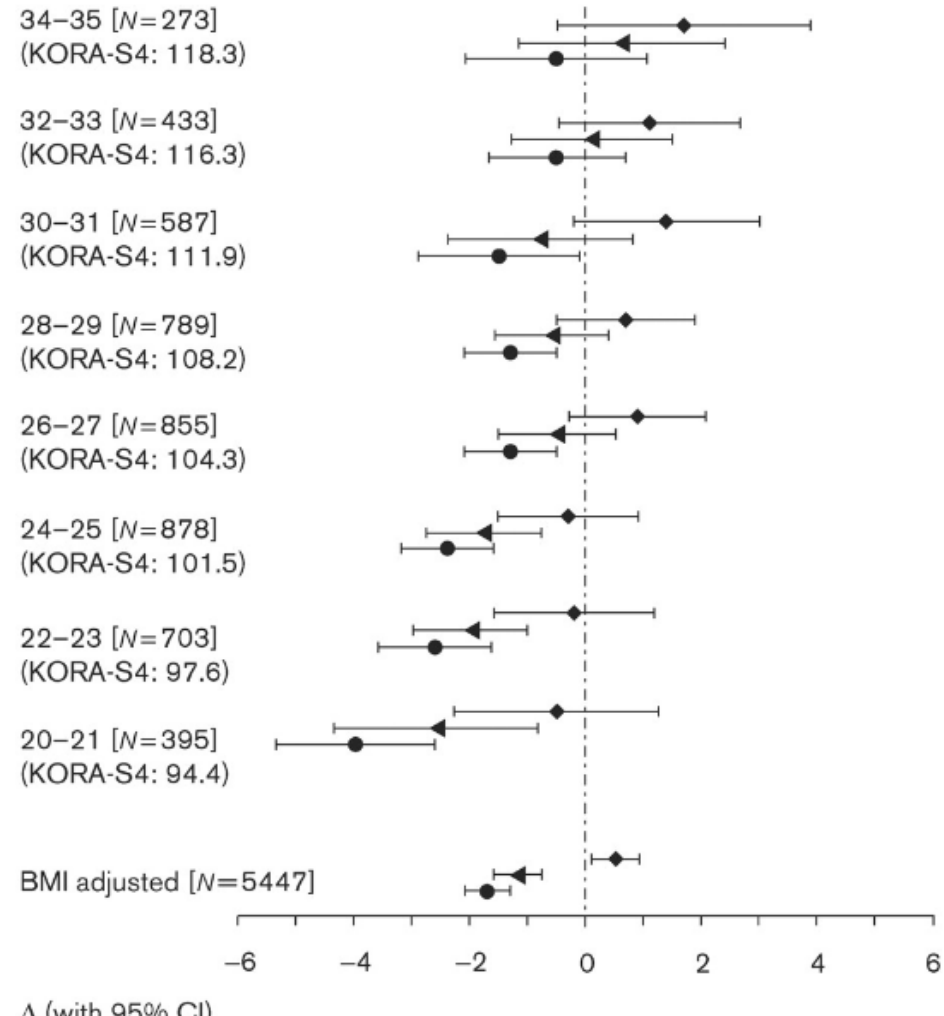

$\Delta$ (with $95 \% \mathrm{Cl}$ )

Women 